\title{
Additive manufacturing ("3D printing") and the future of organizational design: some early notes from the field
}

John M. Jordan(D)

Correspondence: dr.john.jordan@ gmail.com

Penn State University, University Park, PA, USA
Additive manufacturing, commonly and sometimes imprecisely called 3D printing, represents a major change in industrial production. Just as happened with steam power, hydraulics, and assembly lines, changes in production will reshape organizational constraints (particularly related to location) and possibilities (such as being able to address new kinds of markets). Economies of both scale and scope are being redefined and challenged, mass customization of non-software products is now feasible, and previously "impossible" geometries can now be routinely fabricated. We are already seeing incumbents stumble in competition with smaller firms with lighter but more flexible asset bases. Further, global regulatory agencies are challenged by the new possibilities of 3D printing, forcing organizational change onto both the regulators and the regulated entities. While we live in early days in the adoption of 3D printing to make production parts, several organizational design implications are emerging. I will discuss four of these:

(1) Centralization of productive capacity no longer needs to be assumed Managers can now choose how much to concentrate production and how much to decentralize and downscale manufacturing and/or maintenance to the edges of the supply chain

(2) In a properly configured demand chain, organizations can now profitably perform mass customization of manufactured goods

Demand-driven supply chains drive numerous changes in organizational design from procurement through fitting and delivery

(3) Very few companies are designing production for $3 D$ printing, instead retrofitting it onto parts that were conceived and built in traditional mass production facilities Now that additive production is a viable choice, managers must make and implement choices as to what parts in what organizations in which markets will be digitally designed and built in a 3D-native manner

(4) Because 3D printing represents such a departure from established norms, organizational learning is difficult

Numerous functional leaders in many organizations will be forced to weigh the costs and risks to undertake such learning, returns on which are not assured 
In each instance, there is no assumption that $3 \mathrm{D}$ printing will force a certain shift in organizational design, and by no means will it replace most traditional mass production technologies for making long runs of conventional shapes. Rather, with an expanded range of possibilities, existing assumptions will need to be tested. For example, in the realm of decentralization, 3D printing should not be assumed to drive most production from centralized facilities out to the periphery, but neither can centralization continue to be taken as the default. In short, each of the four domains represents a set of decisions that organizational designers and managers will now need to address with conscious deliberation rather than previously constrained assumptions. The interrelationships among these domains of change-and others that will emerge-remain to be discovered.

\section{What is 3D printing/additive manufacturing?}

In the human history of making things, there have been several major steps. In oversimplified terms, people can fabricate in three ways: subtraction (hammering a flint arrowhead or whittling a stick), molding (pouring gold into a sand mold or concrete into forms), and addition (building a log cabin or a pyramid). In the 19th and 20th centuries, advances in machinery increased the power for moving dirt, metal, or concrete, while new steel alloys for cutting tools and other innovations enhanced the precision of subtraction. In the realm of metalworking, however, the precision of subtraction far exceeded the precision of addition: even as recently as the 1990s, CNC (computer numerical control) machine tools as well as laser and waterjet cutters could remove material far more impressively and precisely than anything could add it.

Beginning in the 1980s, however, computers were harnessed to the task of adding minute amounts of material with heretofore impossible precision. Initially, the machines were used to make plastic mock-ups of new computer-aided design (CAD) files and were known as rapid prototyping tools. By the early 1990s, the same approach was adapted to metal. In the 20-plus years since, the advantages of additive manufacturing, as it has come to be called, continue to accumulate, moving beyond prototyping into production.

Why do 3D printing/additive manufacturing (the terms are generally used interchangeably in the industrial sense) matter? Five broad usage scenarios have emerged for additive manufacturing. Two of these are currently niche markets: on-site fabrication in remote locations like offshore oil rigs and printing materials that cannot be traditionally worked. Mass customization (a third market) is emerging as a major opportunity, as for hearing aids and orthodontic applications. Two final markets relate to production parts, where additive manufacturing is best used when complex shapes and/or short production runs of manufactured goods are required. It is important to note that $3 \mathrm{D}$ printing can excel where traditional fabrication was most limited: where molding, stamping, and milling work well, they are likely to remain the methods of choice.

\section{Designing organizations for decentralization}

In some forms of manufacturing, processes that are currently performed in capital-intensive factories, often thousands of miles away from end customers, will 
migrate to smaller facilities. The logic of economies of scale will still apply in some cases, but in others, the increase in responsiveness, personalization, and/or inventory reduction will favor decentralized productive capacity. This decentralization already can be seen in publishing: rather than my university library purchasing a paper volume from a journal, I print out the article I need on my desktop (if I in fact want paper at all).

Navy ships already print some parts on board. Downloadable 3D files are already helping replace broken oven knobs in both restaurant and home kitchens. Auto manufacturers could install small polymer printers at dealers to save on inventory costs for thousands of small but important plastic parts; Mercedes was already 3D printing spare plastic parts for its trucks as of 2016 and began making metal parts a year later (Woodard, 2017). Porsche went a step further and is using additive techniques to recreate obsolete partswith "absolute fidelity to the original specifications" - for its classic models without having to tool up mass production (Porsche Classic supplies classic parts from a 3D printer, 2018). Moving the locus and scale of production in turn affects the size and activities of the purchasing organization, the inventory management function, and of course factories. Previously impossible repairs (such as rebuilding broken teeth on a large, complex, and/or obsolete gear) can become feasible. Forecasts may need to become much more granular, responsive, and localized to reflect smaller production facilities closer to end demand.

At the same time, putting more productive capability closer to end users, without layers of intermediaries, can result in accelerated innovation. The smartphone app industry is a case in point: when enterprise software took huge teams years to write in the 1960 s and 1970 s, there were no social applications, no mass-market computer games, and no integration with GPS (as in Waze) or photography (as in Snapchat). Decentralized makers on shared platforms, running ever more powerful software, and collaborating outside organizational boundaries are likely to make things that large companies never attempted or conceived of (Gershenfeld, 2012).

A company designed from the ground up to exploit the advantages of additive manufacturing will employ new business models, organizational shapes, marketing channels, and other practices.

One example of such an organization is Robot Bike, a British maker of custom-fit mountain bikes. Unique frame geometries are built from additively manufactured custom titanium lugs (joints) that connect to carbon-fiber tubing cut to length. Market reaction has been highly positive (Wight, 2017).

Robot Bike's founders were college classmates who combined their hobby with years of professional experience in aerospace and software-driven manufacturing. Their unique combination of skills and experiences led them to build a new kind of company. On the production side, Robot Bike partners with one manufacturing software company to do topology optimization (which balances size and shape vs strength) for each bicycle part, a different software company to develop digital blueprints for the parts, and a 3D printing vendor to build the actual metal components (Saunders, 2016). On the demand side, the Internet and social media word of mouth help make the startup competitive with established cycling giants, whose supply-push channel cannot readily adapt to demand-pull customization. Thus, a new kind of bike is being built by an organizational model completely unknown in the traditional cycling industry. 


\section{Designing organizations for mass customization}

One new business model is based on mass production of unique items. Hearing aids have already proved the concept, and several startups are expanding the model to additional markets. Invisalign dental straighteners have reinvented the orthodontic market; the parent company was the top performing stock in the S\&P 500 in 2017. Tailored Fits is a Swiss company that began by making custom orthotics for sports shoes and ski boots. (Orthotics have been successfully 3D printed since at least 2010.)

For mass customization to take deep roots in the industrial landscape, the supply chain will need to be reconceived and reconfigured, with significant organizational implications. Much as 3D printers are often tested on builds traditionally performed by subtractive and similar methods and found to be too slow and expensive, and the supply chain model begins with raw materials: the canonical order of operations is plan $\rightarrow$ source $\rightarrow$ make $\rightarrow$ deliver. In both cases, the defining capabilities of additive manufacturing are not being utilized to maximum advantage.

To design a mass customization process from scratch, the key is to begin with unique units of demand: what is it that is being customized and to what parameters? The hearing aid market is instructive in this regard: local audiologists measure the customer's hearing loss and ear dimensions, then feed this data into the process. In the absence of a steady stream of such customized orders, the "mass" in mass customization fails to materialize at economically attractive levels. Where else can customizable goods find willing buyers who can be served by fitters and configurators with access to 3D printing capacity in some shape or form?

Tailored Fits had to design a 3D scanner that measured a customer in an active skiing posture, not standing or sitting passively, and ski shop employees needed to be trained on the device (Materialize and Tailored Fits create digital supply chain for custom-fit ski boots, 2017). One of Invisalign's competitors solves the problem of initiating customized orders by sending out self-fitting kits for dental correction, bypassing the orthodontists that drive Invisalign's sales (Smile Direct Club, n.d). In these instances, productive capacity can remain centralized, but the sales' channel must be (in most cases outside dentistry and audiology) completely reconfigured. As with Robot Bike, Tailored Fits employs a completely different organizational model-a partnership with the Belgian 3D printing equipment provider Materialise-compared to its giant competitors. So too does Invisalign: most orthodontia was performed using artisanal methods in small labs prior to the startup's innovative use of $3 \mathrm{D}$ printing at a national scale.

\section{Designing organizations for 3D-native business processes}

Multiple business processes are redefined when additive manufacturing is found to be feasible. Substantial advantages come with inventory reduction: in a pure demand-pull regime, there is no excess finished-goods inventory because demand is known before production is completed. At the same time, lot sizes of one become possible without the traditional practices of postponement-which is late-stage completion of a product (Ikea furniture is a classic example of postponement, but not customization)—or other modifications of standardized output. A key organizational question revolves around whether to buy the necessary additive capability as a service from an outsourcer or to build productive capacity through capital investment and hiring of people with specialized skills. 
Supply chains got very long in the early 2000s when manufacturers invested heavily in production in cheap-labor regions located far from end customers. Unexpected events of many sorts-from the Icelandic volcano to port strikes to tsunamis-forced a rethinking of the risks of interruption of these long and fragile connections. Now, production of, say, a custom cardiac stent could occur a day before its implantation only a few feet away from its manufacture. Short supply chains for complex and/or customized goods reduce inventory, improve planning accuracy (and thus reduce scrap rates due to unsold inventory), and reduce missed deliveries and other shortages, known in the field as stock-outs.

What will an additive-native organization look like? Strict functional specialization will likely give way to agile generalists: the connections between digital design and digital manufacturing mean that engineers need to know metallurgy and machine operators much be adept with computers. With the potential for easy customization, product design might get much closer to end customers. Procurement of a few powdered materials is orders of magnitude simpler than managing thousands of SKUs. Warehouses filled with work in process or finished goods will shrink if custom items are all built to order.

The use of working capital also improves. Expensive tooling for a long production run does not have to be procured and paid for before a single item is produced. This reduction of sunk costs extends to raw materials: the metal or polymer powder for a single build can easily be expensed, while potentially truckloads of raw metal or polymer compounds are a much costlier proposition for large batches that need to be run in mass production. Finally, the capital investment in additive manufacturing equipment is highly adaptable: it is a thing that can make many different things. In contrast, stampers, molds, and dies are tightly constrained and difficult or impossible to adapt as market conditions change. Thus, the finance and accounting organization will face new parameters, potentially related to flexibility as well as cost. These internal measures will eventually be judged by outside investors and analysts. Eventually, equity markets will expect new performance targets, so earnings guidance will evolve, putting pressure on traditional financial analysis and reporting.

\section{Designing organizations for new kinds of learning}

For years, research in 3D printing was focused on replicating the subtractive and formative manufacturing processes and materials of the past 150 years, albeit in smaller lots. More recently, additive machines have come into their own when entirely new materials become practical. Adidas is teaming with Carbon to 3D print running-shoe midsoles in a lattice framework that was previously impossible to produce. The first run of 100,000 pairs of the $\$ 300$ shoes began shipping in 2018, shortly after Adidas made an investment in the startup and took a seat on Carbon's board. That relationship is likely as much a matter of access to the startup's nimble culture as it is of organic chemistry: the larger organization most likely had too much institutional inertia to innovate on its own in the face of such altered productive constraints.

The most visible additive manufacturing success story to date relates to a fuel nozzle used in jet aircraft engines. GE and its French design partner Safran needed to both improve fuel consumption and reduce emissions. The secret to doing this lay in control of the fuel-air mixture, and a complex nozzle was designed to meet these criteria. It 
proved to be impossible to mass produce using current technologies: 20 parts needed to be welded together, and the tight tolerances made the welds extremely difficult, leading to unacceptably high scrap rates. The team tested an additive approach to mass production using machines preciously devoted to short-run prototypes, and the successful manufacturing of a critical part is now widely cited.

Several aspects of the GE story are worth underlining. First, 3D printing can change performance criteria by significant margins: fuel savings, power, development time, cost, and durability all saw major improvements. Second, rather than being expensive or impossible, design complexity gets inexpensive: in some sense, the bigger limit is the designer's imagination and digital creative tools rather than the capability of the fabrication technology. An example of this trend is the complex biological-looking geometries that result from a specific type of machine learning called generative design software: most are unlikely to have been conceived or drawn by a human designer (Edwards, 2018). Third, the financial metrics of conventional manufacturing had to be managed, in this case through stealth, as GE engineers climbed the learning curve of parts consolidation:

"We took six engineers and told them go and see what portion of the total engine they can print," [Mohammad] Ehteshami says. "We hid them from our financial management, because we didn't want them to cut our budget." (Kellner, 2017)

As long as additive manufacturing-good for complex shapes and/or short runs-is compared to the economics of long-run mass production of uncomplicated shapes, it will be found wanting: powdered metal and plastic can cost 10 times as much as solid stock. Cost accounting, pricing, forecasting, incentives, sales channel, and product design all can be affected by this fundamental change in productive capability. All of these changes relate to the production of the kinds of products at which $3 \mathrm{D}$ printing excels rather than as a wholesale substitution for traditional manufacturing.

\section{Conclusion}

Rather than simply making conventional manufacturing practices obsolete, 3D printing gives the designer, fabricator, sales representative, and repair technician more options. Choosing the right tool for the job becomes a new competency, residing at the intersections of previously siloed skill domains: mechanical engineering, metallurgy, forecasting, industrial engineering, solid-state physics, organic chemistry, project and corporate finance, optics, computer science, data management, and many more. All of these production options in turn generate organizational implications.

One-at-a-time (and just-in-time) spare parts can make warehouses full of aging inventory economically unattractive, changing the design of the spare parts and service functions. Mass customization has been proven to work only in instances where the sales channel can initiate manufacturing with the unique specifications of large numbers of specific customers. Exotic geometries in polymers and metals can be made without welders and other shop floor employees, changing the labor requirements and allocations of a factory. Finally, nimble startups are partnering with producers of additive manufacturing capital equipment in new joint venture and outsourcing models that 
outcompete traditional economies of productive scale-and the organizational mass required to administer and run it.

Previously commonsense definitions-what is a factory, a firm, a product life cycle?must now be rethought and chosen: the old defaults can no longer be assumed. The organizational designs that are emerging-stealth operations inside advanced manufacturers, equity investments in startups by global giants, software-driven custom-manufacturing partnerships-provide some early evidence of the new shapes that will be crafted from intellectual and financial capital, labor, and innovation that radiates outward from the latest innovation in the way people make things.

Author's contributions

The author read and approved the final manuscript.

Competing interests

The author declares that he has no competing interests.

\section{Publisher's Note}

Springer Nature remains neutral with regard to jurisdictional claims in published maps and institutional affiliations.

Received: 29 November 2018 Accepted: 7 February 2019

Published online: 27 February 2019

\section{References}

D Edwards, Lightweighting: how GM and Autodesk are using generative design for vehicles of the future, Robotics and Automation News, 19 July 2018 https://roboticsandautomationnews.com/2018/07/19/how-gm-and-autodesk-are-usinggenerative-design-for-vehicles-of-the-future/18348/

Gershenfeld N (2012) How to make almost anything: the digital fabrication revolution. Foreign Aff 91(6):43-57

T Kellner, An epiphany of disruption: GE additive chief explains how 3D printing will upend manufacturing, GE Reports, 13 November 2017 https://www.ge.com/reports/epiphany-disruption-ge-additive-chief-explains-3d-printing-will-upendmanufacturing/

Materialize and Tailored Fits create digital supply chain for custom-fit ski boots, 31 August 2017 https://www.materialise.com/ en/press-releases/materialise-tailored-fits-digital-supply-chain-ski-boots

Porsche Classic supplies classic parts from a 3D printer (12 February 2018) https://newsroom.porsche.com/en/company/ porsche-classic-3d-printer-spare-parts-sls-printer-production-cars-innovative-14816.html

M Saunders, A 3D printed mountain bike that you can buy today, Renishaw PLC blog post, 7 June 2016 https://www. renishaw.com/en/blog-post-a-3d-printed-mountain-bike-that-you-can-buy-today--38917

Smile Direct Club: How it works (n.d.) https://smiledirectclub.com/how_it_works/

A Wight, First ride: Robot Bike Co. R130 off-road.cc, 20 December 2017 http://off.road.cc/content/news/first-ride-review-robotbike-co-r130-1219

C Woodard, Mercedes can now 3D print metal truck parts, Motor Trend (3 August 2017) https://www.motortrend.com/news/ mercedes-can-now-3d-print-metal-truck-parts/

\section{Submit your manuscript to a SpringerOpen ${ }^{\circ}$ journal and benefit from:}

- Convenient online submission

- Rigorous peer review

- Open access: articles freely available online

- High visibility within the field

- Retaining the copyright to your article 